\title{
DNA damage-inducing agents elicit $\gamma$-secretase activation mediated by oxidative stress
}

\author{
SM Jin ${ }^{1}$, HJ Cho ${ }^{1}$, ES Jung ${ }^{1}$, M-Y Shim ${ }^{1}$ and I Mook-Jung ${ }^{*, 1}$
}

According to the amyloid cascade hypothesis, Alzheimer's disease is the consequence of neuronal cell death induced by $\beta$-amyloid $(A \beta)$, which accumulates by abnormal clearance or production. On the other hand, recent studies have shown cell death-induced alteration in amyloid precursor protein (APP) processing, suggesting potential mutual interactions between APP processing and cell death. We have shown previously that the cell death caused by DNA damage-inducing agents (DDIAs) facilitated $\gamma$-secretase activity and $A \beta$ generation in a Bax/Bcl-2-dependent, but caspase-independent manner. Here, we attempted to elucidate the downstream mechanism that modulates $\gamma$-secretase activity in DDIA-treated cells. $N$-acetyl cysteine, a potent antioxidant, attenuated DDIA-induced enhancement of $\gamma$-secretase activity but failed to rescue cell death. Overexpression of heat shock protein 70 , which blocks cytochrome $c$ release from mitochondria, also reduced $\gamma$-secretase activity. Moreover, glutathione depletion significantly facilitated $\gamma$-secretase activity and $A \beta$ generation by enhancing the formation of higher molecular weight $\gamma$-secretase complex before signs of cell death developed. Finally, $A \beta$ treatment, a known inducer of oxidative stress, also increased $\gamma$-secretase activity. Taken together, these results indicate that DDIA-induced $\gamma$-secretase activation is dependent on augmented oxidative stress, and that $A \beta$ and $\gamma$-secretase may activate each other. On the basis of these results, we propose a feed-back loop between oxidative stress and $A \beta$ generation mediated by $\gamma$-secretase activation.

Cell Death and Differentiation (2008) 15, 1375-1384; doi:10.1038/cdd.2008.49; published online 18 April 2008

Alzheimer's disease (AD) is a neurodegenerative disease caused by chronic loss of synapses and neuronal cell death. The senile plaque, the pathological hallmark of $A D$, is composed of a short peptide called $\beta$-amyloid $(\mathrm{A} \beta) .{ }^{1} \mathrm{~A} \beta$ is known to impair synaptic transmission and neuronal viability. According to the amyloid cascade hypothesis, abnormal production or insufficient clearance of these peptides is the cause of AD. ${ }^{2}$

$\beta$ - and $\gamma$-secretases are the enzymes responsible for $\mathrm{A} \beta$ generation by the sequential cleavage of amyloid precursor protein (APP). Therefore, targeting $\gamma$-secretase can be an effective therapeutic strategy to prevent and treat $A D$. However, $\gamma$-secretase excises more than 25 substrates besides $\mathrm{APP},{ }^{3}$ and its complete absence or inhibition has been reported to have severe side effects in knockout, conditional double-knockout, and inhibitor-treated mice. ${ }^{4-6}$ Therefore, an alternative may be to modulate the activity of $\gamma$-secretase to a more tolerable degree. To this end, it is critical to understand the regulatory mechanisms of $\gamma$-secretase activity.

Nevertheless, although neuronal death is the direct cause of $A D$, researchers have not focused on the alteration of APP processing during neuronal cell death, and there are few reports that describe the increased production of $\mathrm{A} \beta$ under apoptotic conditions, such as $\mathrm{KCl}$ deprivation or cytotoxic drug treatment. ${ }^{7,8}$ We recently reported evidence that $\gamma$-secretase activity and $\mathrm{A} \beta$ generation were upregulated in a $\mathrm{Bax} / \mathrm{Bcl}-2-$ dependent and caspase-independent manner during DNA damage-inducing agent (DDIA)-induced apoptosis. ${ }^{9}$

Apoptotic pathways can be categorized into two subtypes the intrinsic, mitochondrial-mediated pathway and the extrinsic, death receptor-initiated pathway. ${ }^{10}$ Cytotoxic drugs, such as etoposide (Eto) and camptothecin (Cmt), and also UV and $\gamma$-irradiation, are known to trigger the intrinsic pathway of apoptosis. ${ }^{10}$ Cytochrome $c$ (CytC) released from mitochondria, together with dATP, apoptotic protease-activating factor1 (Apaf1), and procaspase-9, forms complexes called apoptosomes. Procaspase- 9 is cleaved to active caspase- 9 , which is followed by activation of downstream effector caspases.

Reactive oxygen species are involved in the induction or enhancement of apoptosis. Small quantities of reactive oxygen species (ROS), including superoxide anions $\left(\mathrm{O}^{\bullet}{ }^{-}\right)$, hydrogen peroxide $\left(\mathrm{H}_{2} \mathrm{O}_{2}\right)$, and hydroxyl radicals $(\bullet \mathrm{OH})$, are continuously generated in mitochondria as a consequence of oxidative phosphorylation. The production of ROS increases dramatically upon stress stimulation, such as that imposed by cytotoxic agents, UV, or $\gamma$-irradiation.

\footnotetext{
${ }^{1}$ Department of Biochemistry and Cancer Research Institute, Seoul National University College of Medicine, Seoul, Korea

${ }^{*}$ Corresponding author: I Mook-Jung, Department of Biochemistry and Cancer Research Institute, Seoul National University College of Medicine, 28 Yeongon-dong, Jongno-gu, Seoul 110-799, Korea. Tel: + 82-2-740-8245; Fax: + 82-3672-7352;

E-mail: inhee@snu.ac.kr

Keywords: oxidative stress; reactive oxygen species; $\gamma$-secretase; Alzheimer's disease; DNA damage-inducing agent

Abbreviations: $\mathrm{AD}$, Alzheimer's disease; A $\beta$, amyloid- $\beta$; APP, amyloid precursor protein; BN-PAGE, blue native-polyacrylamide gel electrophoresis; CAT, catalase; Cmt, camptothecin; CyA, cyclosporine A; CytC, cytochrome $C$; DDIA, DNA damage-inducing agent; DEM, diethyl maleate; dUbq, decylubiquinone; Eto, etoposide; Fmt, sodium formate; GSH, reduced glutathione ethyl ester; Hsp, heat shock protein; L-NAME, L- $N^{G}$-nitro-L-arginine methyl ester; MPTP, mitochondrial permeability transition pore; NAC, N-acetyl cysteine; Nct, nicastrin; PS, presenilin; RNS, reactive nitrogen species; ROS, reactive oxygen species; SOD, superoxide dismutase; STS, staurosporine

Received 21.9.07; revised 28.2.08; accepted 18.3.08; Edited by L Greene; published online 18.4.08
} 
Oxidative stress also plays a key role in the initiation and progression of $A D$, inducing neuronal cell death by damaging cell membranes and the cytoskeleton. ${ }^{11}$ Tamagno et al. ${ }^{12}$ reported that the oxidative stress induced by such insults as ascorbate/ $\mathrm{FeSO}_{4}, \mathrm{H}_{2} \mathrm{O}_{2} / \mathrm{FeSO}_{4}$, and 4-hydroxynonenal increased the expression and activity of $\beta$-secretase (BACE1). Notably, $\mathrm{A} \beta$ treatment, known to increase intracellular oxidative stress levels in vivo and in vitro, ${ }^{13,14}$ also upregulated BACE1 expression and activity. ${ }^{15}$ However, the correlation between oxidative stress and $\gamma$-secretase activation has not been reported.

On the basis of our previous report that DDIA-induced $\gamma$-secretase activation was blocked by overexpression of Bcl-2 or treatment with furosemide (a Bax translocation blocker) but not by downstream caspase inhibitor treatment, we attempted to determine the association of oxidative stress during apoptosis with $\gamma$-secretase activation.

\section{Results}

DDIA-induced oxidative stress enhances $\gamma$-secretase activity and $\mathbf{A} \boldsymbol{\beta}$ generation. In our previous report, $\mathrm{Bcl}-2$ overexpression and furosemide treatment significantly lowered $\gamma$-secretase activation by DDIAs, and here we explored the possibility that increased ROS or reactive nitrogen species (RNS) in mitochondria are responsible for $\gamma$-secretase activation.

$\mathrm{CHO}-\mathrm{C} 99$ cells, $\mathrm{CHO}$ cells containing a luciferase reporter system for $\gamma$-secretase activity, ${ }^{9}$ were treated with Eto or Cmt, and ROS and RNS levels were measured in a fluorescence assay involving the oxidation of nonfluorescent $2^{\prime}, 7^{\prime}$-dichlorodihydrofluorecein diacetate $\left(\mathrm{H}_{2} \mathrm{DCFDA}\right)$ to fluorescent dichlorofluorescein (DCF), as well as by changes in intracellular glutathione levels in a colorimetric assay based on the oxidation of glutathione (GSH) by 5,5'-dithio-bis-(2-nitrobenzoic acid) (DTNB), as described in Materials and Methods.

We detected the gradual increase of intracellular oxidative stress. The activation of $\gamma$-secretase was detected at $48 \mathrm{~h}$ after Eto treatment and $24 \mathrm{~h}$ after $\mathrm{Cmt}$ treatment. This activation coincided with the increase of ROS or RNS and the decrease of intracellular glutathione (Figure $1 \mathrm{a}$ and $\mathrm{b}$ ). To examine whether this concurrence was relevant to the mechanisms of $\gamma$-secretase activation, we treated cells with various antioxidants of ROS and RNS. In both cases of DDIA, the potent antioxidant $\mathrm{N}$-acetyl cysteine (NAC; $1 \mathrm{mM}$ ) effectively reduced the activation of $\gamma$-secretase, and the cell-permeable form of reduced glutathione (glutathione ethyl ester; GSH; $5 \mathrm{mM}$ ) also significantly lowered $\gamma$-secretase activity. However, the nitric oxide synthase inhibitor $L-N^{G}$ nitro-L-arginine methyl ester (L-NAME; $100 \mu \mathrm{M}$ ) had no effect on $\gamma$-secretase activity (Figure $1 \mathrm{c}$ and $\mathrm{d}$ ). The basal activity was not affected by these antioxidants (Supplementary Figure 1). These results suggest that the ROS generated by DDIA treatment are responsible for the activation of $\gamma$-secretase.

To confirm the effect of antioxidants on $\mathrm{A} \beta$ generation, the level of $\mathrm{A} \beta$ secretion was measured in $\mathrm{CHO}$-swAPP cells $\mathrm{CHO}$ cells overexpressing human Swedish APP - treated as above. Increased $A \beta_{40}$ was reduced to near control levels by NAC, but not by L-NAME (Figure 1e and $\mathrm{f}$, upper panel). $\mathrm{A} \beta_{42}$ was not detected in a range in this cell line. Total APP levels indicated that the change in $A \beta$ generation was not due to the change in APP levels because APP levels were constant (Figure 1e and f, lower panel). Interestingly, ROS scavengers failed to rescue cell death (Figure $1 \mathrm{~g}$ and $\mathrm{h}$ ), indicating that the effect of antioxidants was not a result of the inhibition of cell death.

ROS responsible for $\gamma$-secretase activation is generated from CytC-depleted mitochondria. In mitochondria, superoxide is first generated and converted to $\mathrm{H}_{2} \mathrm{O}_{2}$ by superoxide dismutase (SOD), and superoxide or $\mathrm{H}_{2} \mathrm{O}_{2}$ is transformed to hydroxyl radicals by Fenton reaction or Haber-Weiss reaction. ${ }^{16}$ To examine the kind of ROS that was responsible for $\gamma$-secretase activation among these, we treated the scavenging enzymes or chemical for each specific ROS to the cells. Both catalase (CAT) - the scavenger for $\mathrm{H}_{2} \mathrm{O}_{2}$ - and sodium formate (Fmt) - the scavenger for hydroxyl radicals - significantly reduced DDIAelicited $\gamma$-secretase activity, whereas SOD - the scavenger for superoxides - failed to block $\gamma$-secretase activation (Figure $2 \mathrm{a}$ and $\mathrm{b}$ ). To confirm whether the main source of ROS generated by DDIA treatment is mitochondrial electron transport chain, we examine the contribution of another known source of ROS, that is, xanthine oxidase and $\mathrm{NAD}(\mathrm{P}) \mathrm{H}$ oxidase. As shown in Figure $2 \mathrm{c}$ and $\mathrm{d}$, xanthine oxidase-specific inhibitor, allopurinol (Allo), and $\mathrm{NAD}(\mathrm{P}) \mathrm{H}$ oxidase inhibitor, apocynin (Apo), failed to block $\gamma$-secretase activation by DDIA treatment (Figure $2 \mathrm{c}$ and $\mathrm{d}$ ). These results indicate that mitochondrially generated ROS, especially $\mathrm{H}_{2} \mathrm{O}_{2}$ and hydroxyl radicals, are responsible for $\gamma$-secretase activation.

It has been reported that when the intrinsic apoptosis pathway is turned on, CytC is released from mitochondria, and the depleted mitochondria harbor the generation of ROS. ${ }^{10}$ When DDIAs were applied, CytC levels released in the cytosol increased in a time-dependent manner as previously reported (Figure 3a). ${ }^{17}$ To confirm that the increased $\gamma$-secretase activity by DDIA treatment was mediated by mitochondrial ROS due to the depletion of CytC, we overexpressed heat shock protein 70 (Hsp70), which is known to inhibit the release of CytC from mitochondria, ${ }^{18}$ in $\mathrm{CHO}-\mathrm{C} 99$ cells. The overexpression of Hsp70 effectively blocked CytC release from mitochondria to the cytosol and thus significantly reduced the $\gamma$-secretase activity (Figure $3 b$ and $c$ ).

MPTP blockers have no effect on DDIA-induced $\gamma$-secretase activation. Because of controversy surrounding whether mitochondrial permeability transition pore (MPTP) blocker has any effect on the release of CytC, ${ }^{19-21}$ we attempted to resolve whether MPTP blocker impaired DDIA-induced $\gamma$-secretase activation in our experimental system. Treatment with cyclosporine A (CyA; $0.5 \mu \mathrm{M})$, known to inhibit MPTP opening by binding to cyclophiline $D$, or another MPTP inhibitor, decylubiquinone (dUbq; $50 \mu \mathrm{M}$ ), showed no effect on the release of CytC following activation of $\gamma$-secretase by DDIA in $\mathrm{CHO}-\mathrm{C} 99$ cells (Figure $4 \mathrm{a}$ and $\mathrm{b}$ ). Moreover, cell death was also unaffected by MPTP blocker (Figure 4c and d), suggesting that blockage of 

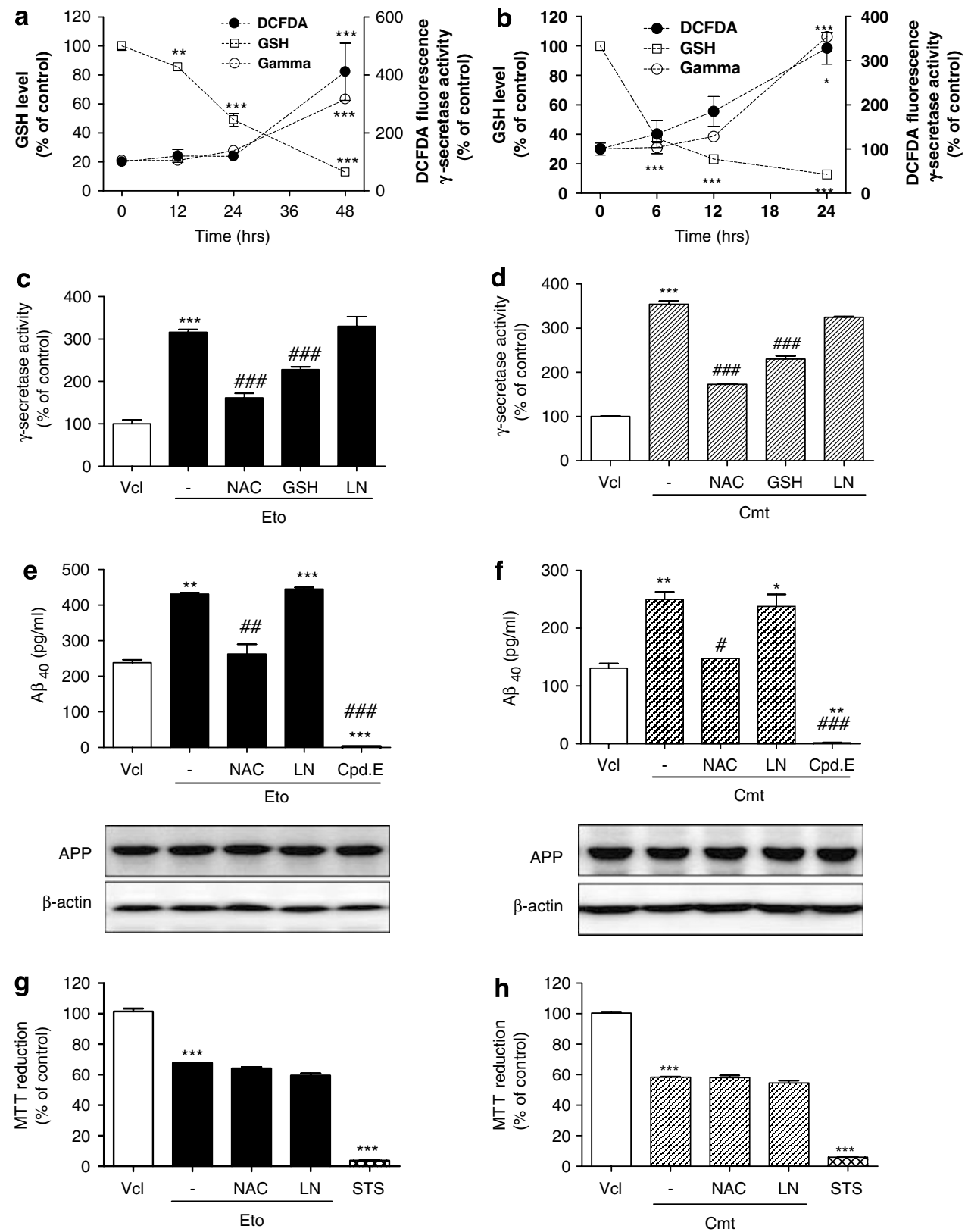

Figure 1 DDIA increased oxidative stress and $\gamma$-secretase activity, resulting in A $\beta$ generation. (a and $\mathbf{b}$ ) CHO-C99 cells were treated with genotoxic agents (Eto, $100 \mu \mathrm{M}$ (a); $\mathrm{Cmt}, 25 \mu \mathrm{M}(\mathbf{b}))$. ROS-reactive fluorescence (filled circle), intracellular glutathione levels (open square), and $\gamma$-secretase activity (open circle) were assayed at indicated time point as described in Materials and Methods. (c and d) CHO-C99 cells were pretreated with NAC, GSH, or L-NAME at 30 min before DDIA treatment. Eto (100 $\mu \mathrm{M}$; (c)) or $\mathrm{Cmt}(25 \mu \mathrm{M}$; (d)) was administered for 48 or $24 \mathrm{~h}$, respectively, after serum depletion for $24 \mathrm{~h}$, and then $\gamma$-secretase activity was measured by luciferase reporter assay. (e and f) CHO-swAPP cells treated as in (c) and (d) and conditioned media were used for A $\beta$ ELISA. Compound E (Cpd.E; $1 \mu \mathrm{M})$ was used to address the assay specificity. Total APP level was assessed by immunoblotting with 22C11 monoclonal antibody. ( $\mathbf{g}$ and $\mathbf{h}$ ) MTT assay was conducted to measure cell viability of $\mathrm{CHO}-\mathrm{C} 99$ cells treated as in (c) and (d). STS $(1 \mu \mathrm{M})$-treated sample was used as positive control. Data are presented as mean \pm S.E. of three independent experiments performed in triplicate. ${ }^{*} P<0.05$, ${ }^{* *} P<0.01,{ }^{* \star *} P<0.001$ versus vehicle-treated samples; ${ }^{\#} P<0.05,{ }^{\# \#} P<0.01$, ${ }^{\# \#} P<0.001$ versus DDIA-treated samples. Eto; filled bar and Cmt; hatched bar

only MPTP is insufficient for decreasing CytC release following $\gamma$-secretase activation and apoptosis in our system.

Glutathione depletion and $\mathbf{A} \beta$ treatment increase $\gamma$-secretase activity and $\mathbf{A} \boldsymbol{\beta}$ generation. To confirm whether increased $\gamma$-secretase activity resulted from increased oxidative stress, we treated $\mathrm{CHO}-\mathrm{C} 99$ cells with diethyl maleate (DEM), an intracellular glutathione-depleting agent. This treatment led to a dose-dependent increase in $\gamma$-secretase activity and DCF fluorescence, as well as a dose-dependent decrease of intracellular glutathione over $6 \mathrm{~h}$ (Figure 5a). But, as shown in Figure 5b, DEM treatment did not decrease cell viability in this period. To address whether this increase of $\gamma$-secretase activity was linked to the elevation of $\mathrm{A} \beta$ secretion, we administered DEM to primary cortical cultures from Tg2576, human Swedish 

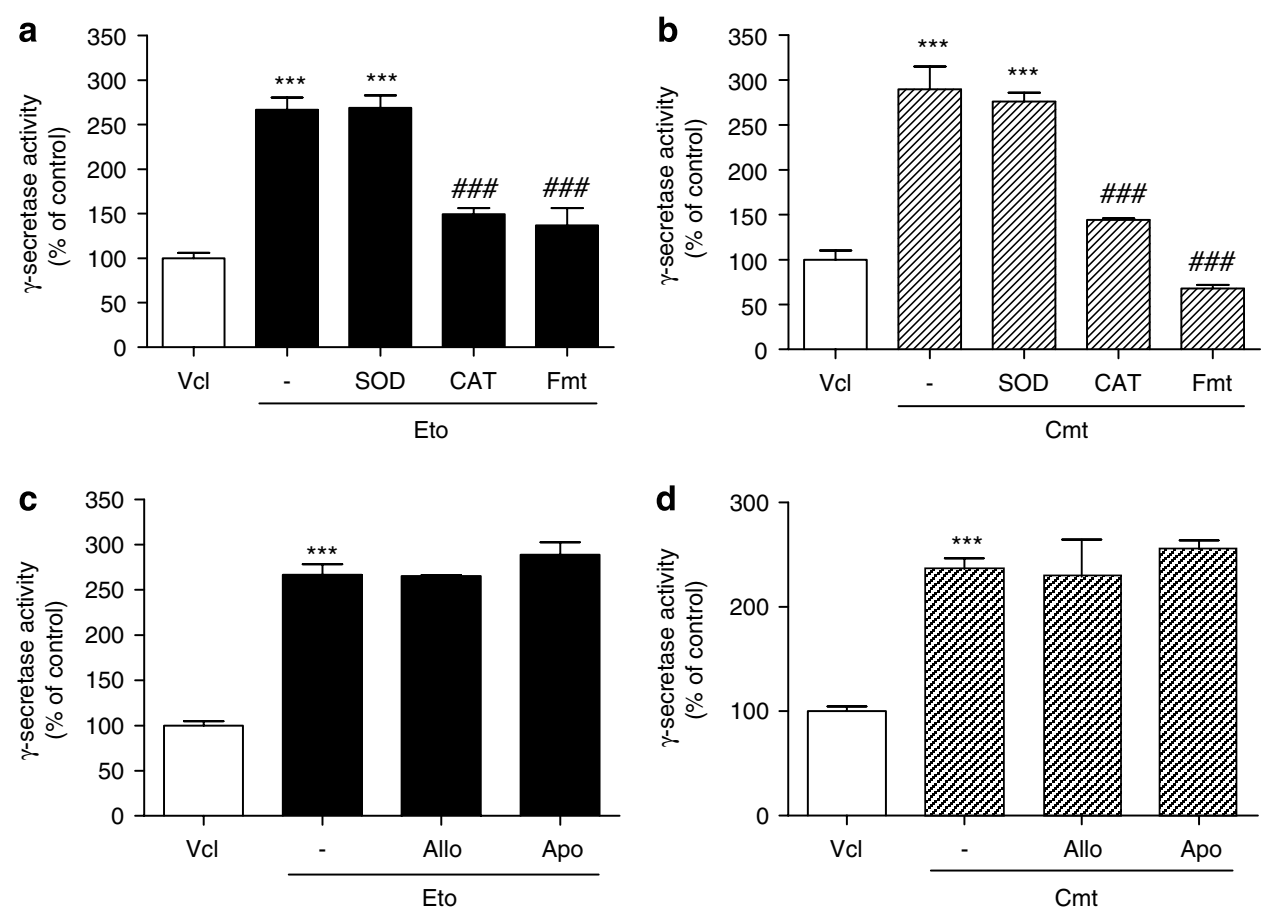

Figure 2 Hydrogen peroxide and hydroxyl radicals were important for DDIA-induced $\gamma$-secretase activation. CHO-C99 cells were pretreated with superoxide dismutase (SOD; $1000 \mathrm{U} / \mathrm{ml}$ ), catalase (CAT; $5000 \mathrm{U} / \mathrm{ml}$ ), sodium formate (Fmt; $10 \mathrm{mM}$ ) (a and b), allopurinol (Allo; $100 \mu \mathrm{M})$, or apocynin (Apo; $100 \mu \mathrm{M})$ (c and d) for $30 \mathrm{~min}$ and then treated with DDIA ( (a and c) Eto; $100 \mu \mathrm{M}, 48 \mathrm{~h}$, filled bar; (b and d) $\mathrm{Cmt} ; 25 \mu \mathrm{M}, 24 \mathrm{~h}$, hatched bar). Luciferase activity was measured to examine $\gamma$-secretase activity. Data are presented as mean \pm S.E. of three independent experiments performed in triplicate. ${ }^{* \star \star} P<0.001$ versus vehicle-treated sample; ${ }^{\# \# \#} P<0.001$ versus DDIA-treated sample

a
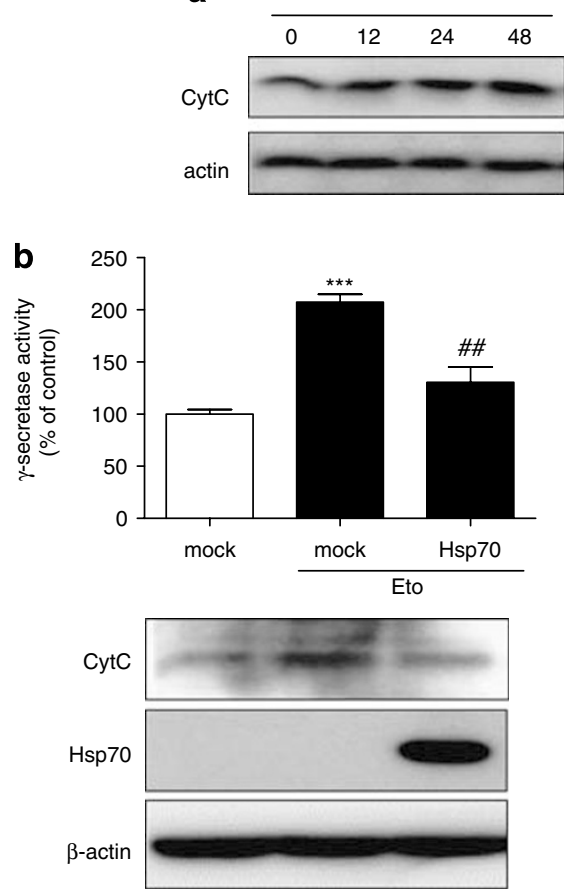
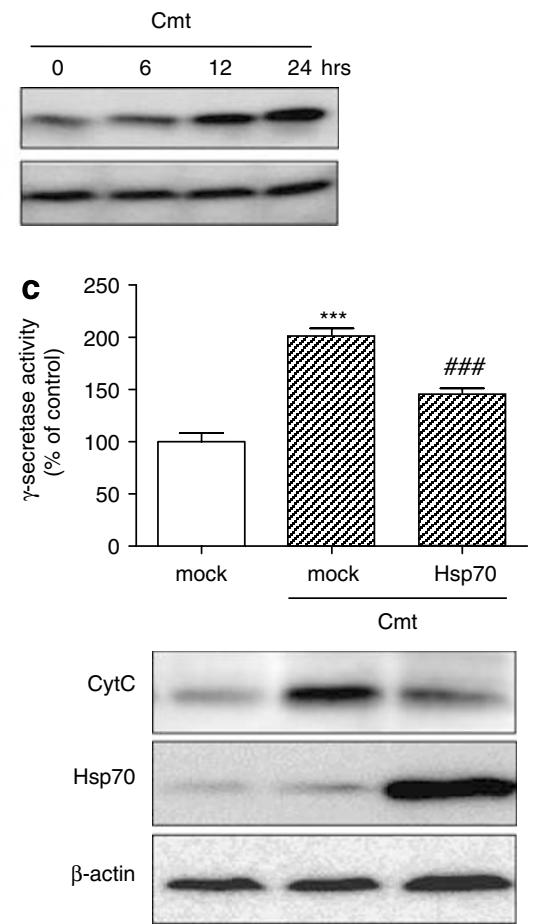

Figure 3 Blocking CytC release attenuated DDIA-elicited $\gamma$-secretase activity. (a) CHO-C99 cells were treated with DDIA (Eto, $100 \mu \mathrm{M}$; Cmt, $25 \mu \mathrm{M}$ ) for indicated time periods. Cells were fractionated, and resulting cytosolic fractions were subjected to immunoblotting with anti-CytC antibody. (b and c) Hsp70 was overexpressed in $\mathrm{CHO}-\mathrm{C} 99$ cells, and then DDIAs were given ((b) Eto; $100 \mu \mathrm{M}, 48 \mathrm{~h}$; (c) $\mathrm{Cmt} ; 25 \mu \mathrm{M}, 24 \mathrm{~h}$ ). Cytosolic proteins were isolated and assayed for $\gamma$-secretase activity by luciferase assay and for the release of $\mathrm{CytC}$ by immunoblotting. Anti-Hsp70 antibody was used to confirm Hsp70 expression, and anti- $\beta$-actin antibody was used to determine loading controls. Data are presented as mean \pm S.E. of three independent experiments performed in triplicate. ${ }^{\star \star \star} P<0.001$ versus vehicle-treated sample; ${ }^{\# \#} P<0.01$, ${ }^{\# \#} P<0.001$ versus DDIAtreated sample. Eto; filled bar and $\mathrm{Cmt}$; hatched bar 

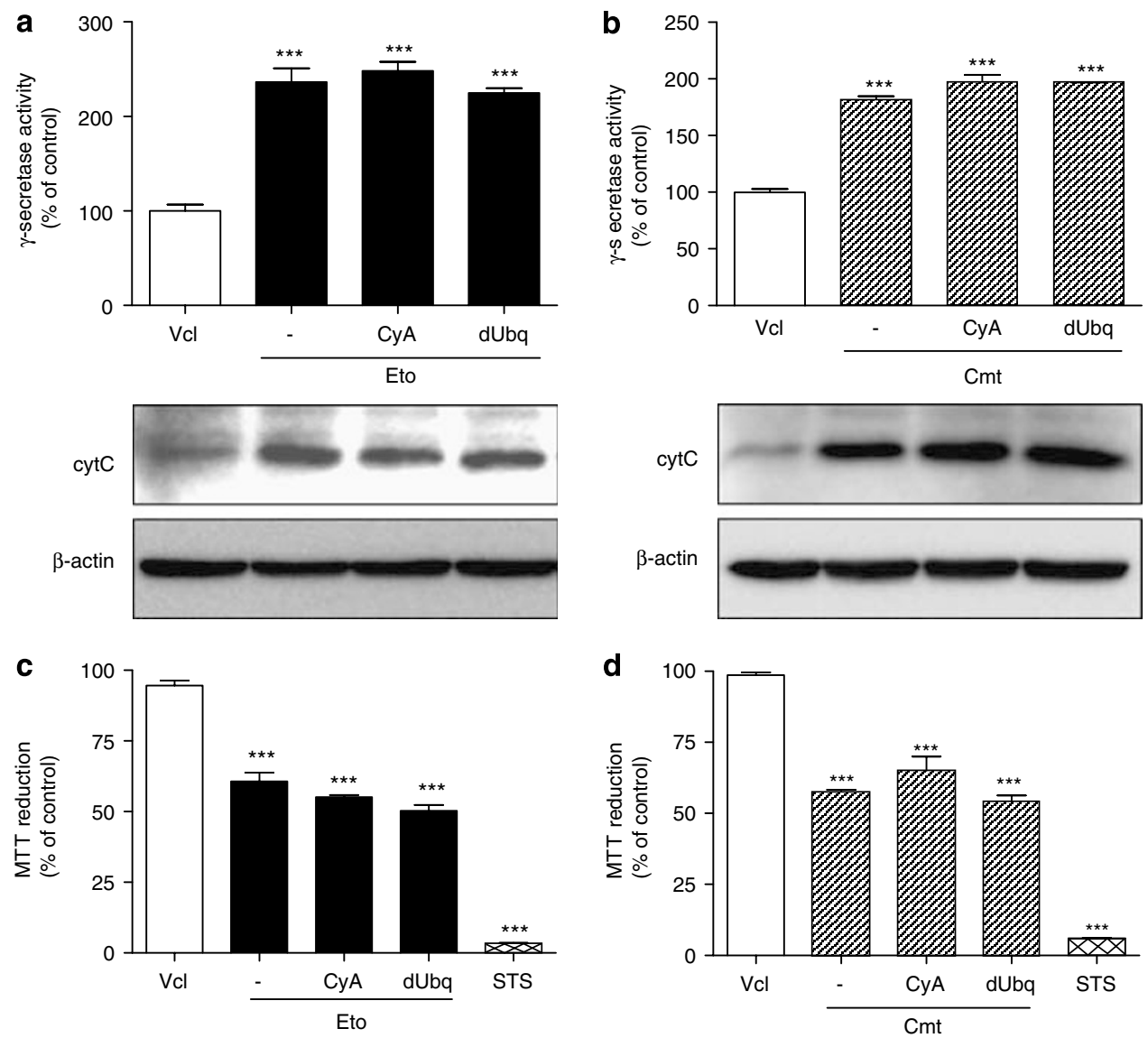

Figure 4 MPTP inhibitors had no effect on DDIA-elicited $\gamma$-secretase activation. (a and $\mathbf{b})$ MPTP blockers were administered for 30 min prior to treatment with DDIA. At the end of treatment with DDIA ((a) Eto, $48 \mathrm{~h}$; (b) $\mathrm{Cmt}, 24 \mathrm{~h})$, luciferase activity was measured. To detect CytC release, CHO-C99 cells were treated as above and then fractionated. The cytosolic fraction was analyzed by immunoblotting for CytC and $\beta$-actin. (c and d) Cell viability was assessed by MTT assay. STS (1 $\mu \mathrm{M})$-treated samples were used as positive control. Data are presented as mean \pm S.E. of three independent experiments performed in triplicate. ${ }^{* \star *} P<0.001$ versus vehicle-treated sample. Eto; filled bar and $\mathrm{Cmt}$; hatched bar

APP-overexpressing mice. Similar to $\gamma$-secretase activation, $\mathrm{A} \beta_{40}$ and $\mathrm{A} \beta_{42}$ levels were also increased by DEM treatment in a dose-dependent manner (Figure 5c) without any changes observed in $A \beta_{40 / 42}$ ratio and APP levels (Figure $5 d$ and e).

As it is well known that $A \beta$ also increases oxidative stress via several pathways, ${ }^{22,23}$ we examined whether the oxidative stress generated by exogenous treatment with $A \beta$ increased $\gamma$-secretase activity. CHO-C99 cells treated with synthetic $\mathrm{A} \beta_{42}$ peptide for $24 \mathrm{~h}$ indeed showed increased $\gamma$-secretase activity in a dose-dependent manner (Figure 5f).

Oxidative stress enhances the formation of high molecular weight $\gamma$-secretase complex. As the protein levels of each $\gamma$-secretase component in total lysates were not changed in our previous report, ${ }^{9}$ we explored the mechanism that can regulate the $\gamma$-secretase activity without affecting protein levels. To test the possibility that the amount of active $\gamma$-secretase complex is affected, we tried blue native-polyacrylamide gel electrophoresis (BNPAGE). $\gamma$-secretase is known to form several kinds of high molecular weight complexes of $220 \sim 250,400 \sim 500$, and $800 \sim 1000 \mathrm{kDa} .{ }^{24}$ We could detect $\gamma$-secretase complexes of those molecular weights with anti-Pen-2 antibody. By DEM treatment, $\gamma$-secretase complex having high molecular weight ( $>800 \mathrm{kDa}$ ) was increased, whereas that having low molecular weight complex $(400 \sim 500 \mathrm{kDa})$ was decreased (Figure 6, upper panel). Pretreatment of NAC inhibited the change of complex pattern. At the same time, the expression levels of each component remained unchanged (Figure 6, lower panel).

\section{Discussion}

The generation of $\mathrm{A} \beta$, through sequential cleavage of APP by $\beta$ - and $\gamma$-secretase, is considered to be the most critical step in the pathogenesis of AD. Recently, due to the importance of these secretases as drug targets for $A D$ treatment, concerted efforts have been devoted to elucidating the regulatory mechanisms of these enzymes, leading to a greater understanding of these two aspartic proteases.

However, $\gamma$-secretase has certain characteristics that differentiate it from other enzymes, which makes it more difficult to understand its biology: (1) it is a multimeric protein, composed of at least four proteins - Presenilin (PS), Nicastrin (Nct), Pen-2, and Aph-1; (2) the expression of these four proteins is very tightly regulated and affected each other; (3) except for Nct, the proteins are very hydrophobic; and (4) the 

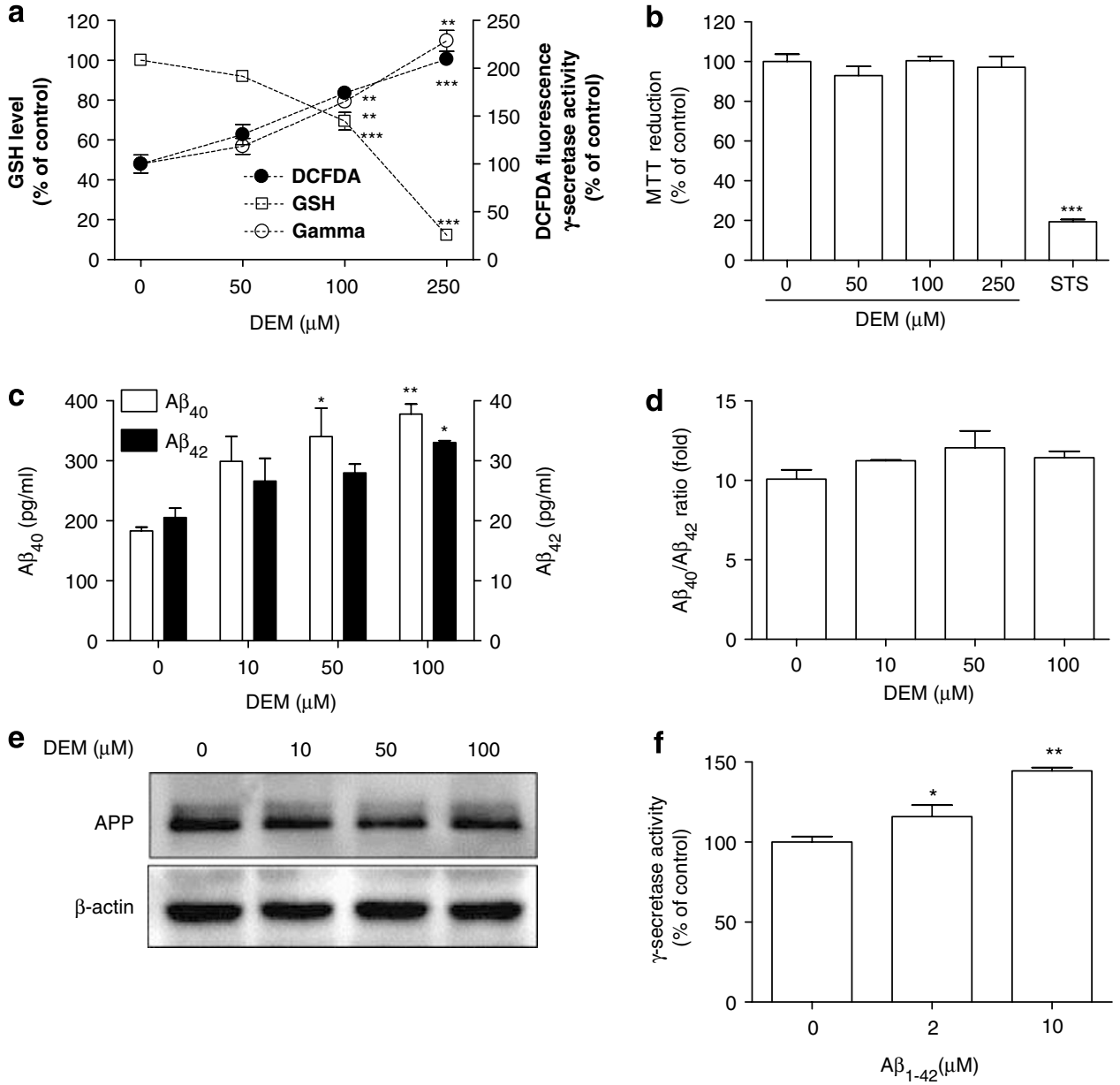

Figure 5 Glutathione depletion and A $\beta$ treatment increased $\gamma$-secretase activity and A $\beta$ generation. (a) CHO-C99 cells were treated with DEM at indicated concentrations for $6 \mathrm{~h}$ and ROS-reactive fluorescence (filled circle), intracellular glutathione levels (open square), and $\gamma$-secretase activity (open circle) were measured. (b) Cytotoxicity of DEM treatment for $6 \mathrm{~h}$ at indicated concentration was measured using MTT assay. STS $(1 \mu \mathrm{M})$-treated samples were used as positive control. (c and d) Primary cortical cultures from Tg2576 mice brains at postnatal day 1 were treated with DEM at the indicated concentrations for $6 \mathrm{~h}$, and secreted $\mathrm{A} \beta_{40}$ (open bar) and $A \beta_{42}$ (closed bar) levels were measured from conditioned media as described in Materials and Methods (c) and A $\beta_{40 / 42}$ ratios were calculated (d). (e) Protein extracts were immunoblotted for APP. (f) $\mathrm{CHO}-\mathrm{C} 99$ cells were treated with synthetic $\mathrm{A} \beta_{1-42}$ peptide for $24 \mathrm{~h}$ and then assayed for luciferase activity. Data are presented as mean \pm S.E. of three independent experiments performed in triplicate. ${ }^{\star} P<0.05,{ }^{* \star} P<0.01,{ }^{* \star *} P<0.001$ versus vehicle-treated sample

mechanisms of intramembranous cleavage are quite different from those of general endopeptidases. Because of these issues, advances in understanding $\gamma$-secretase have been impeded.

As a contribution to these advances, we demonstrated that $\gamma$-secretase activity is facilitated during DDIA-induced apoptosis. ${ }^{9}$ Here, we provide evidence that the $\gamma$-secretasedependent cleavage of APP is under stimulatory control by ROS during DDIA-induced apoptosis. This finding is further supported by the increase of $\gamma$-secretase-mediated cleavage of APP upon treatment with DEM, which depletes intracellular glutathione. Our results also provide evidence that increased $\mathrm{A} \beta$, in turn, activates $\gamma$-secretase, possibly by stimulating ROS generation.

It is well known that oxidative stress is one of the major contributing factors for $\mathrm{AD}$ pathogenesis. For example, Paola et $a l^{25}$ and Frederikse et $a l^{26}$ reported that intracellular $\mathrm{A} \beta$ production increased as a result of oxidative stress in culture systems. In addition, Aplet et al. ${ }^{27}$ established the correlation between aging-related increases in oxidative stress and $\beta$-secretase activity with $\mathrm{A} \beta$ plaque formation in a mouse model of $A D$.

Apoptosis is frequently accompanied by the generation of ROS, resulting in part from mitochondrial release of CytC following disruption of the electron transport chain, even in the absence of downstream caspase activation. ${ }^{28}$ In our previous report, caspase inhibitor treatment failed to block the activation of $\gamma$-secretase elicited by DDIA treatment. ${ }^{9}$ As this finding does not provide a causal correlation of $\gamma$-secretase activity, we further examined the relationship among DDIAinduced apoptosis, oxidative stress, and $\gamma$-secretase activity. Our present study shows that intracellular ROS or RNS increased dramatically and that glutathione levels declined substantially with DDIA treatment (Figure $1 a$ and $b$ ). The relevance of increased ROS to $\gamma$-secretase activation was proven by the effect of antioxidants (Figure 1c and d). Moreover, our results demonstrating the blockage of $\gamma$-secretase activation and CytC release by Hsp70 overexpression and the ineffectiveness of inhibitors for xanthine oxidase and $\mathrm{NAD}(\mathrm{P}) \mathrm{H}$ oxidase strongly implied that ROS 


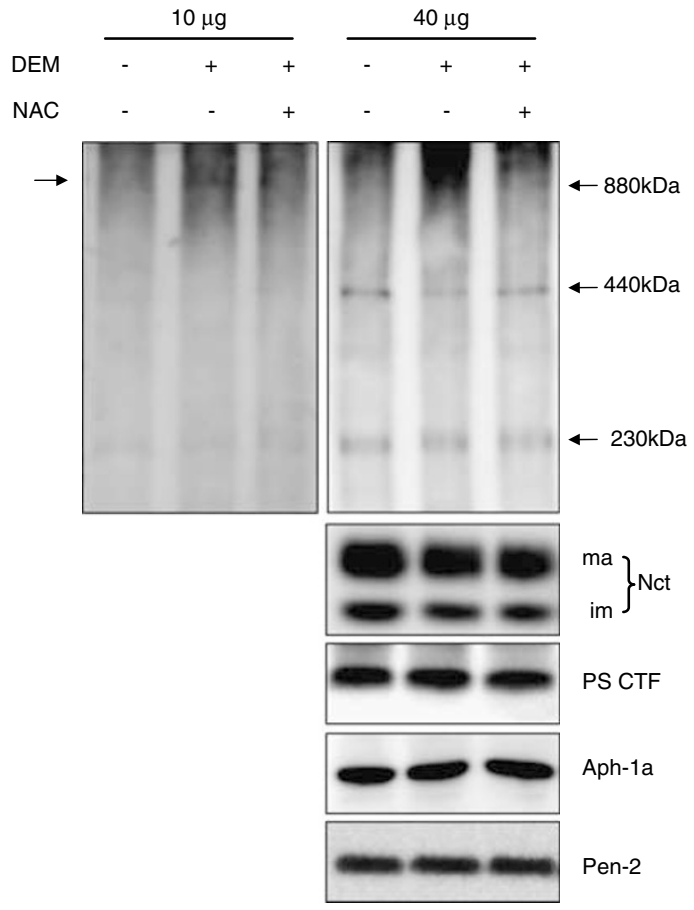

Figure 6 Oxidative stress enhanced the formation of active $\gamma$-secretase complex. Membrane fractions were prepared from $\mathrm{CHO}-\mathrm{C} 99$ cells treated with vehicle, DEM $(250 \mu \mathrm{M})$, or DEM + NAC $(2 \mathrm{mM})$ for $6 \mathrm{~h}$. Membrane proteins were applied for the BN- or SDS-PAGE as described in the Materials and Methods. Representative data from three independent experiments are shown

were generated from the mitochondrial electron transport chain and corresponded to the previous report that $\mathrm{Bcl}-2$ overexpression attenuated DDIA-elicited $\gamma$-secretase activation (Figure 2 and 3 ). ${ }^{9}$

In Figure 1a, the decrease of glutathione in response to the treatment of genotoxic agent preceded the increase of ROS. As glutathione is known to participate and be depleted in detoxification of xenobiotics, it might be possible that the rapid decrease of glutathione is related to the detoxification of DDIA rather than ROS. Though the decreased level of intracellular glutathione could still contribute to oxidative stress, ROS production was delayed to late time point. It implies that the increase of $\gamma$-secretase activity is mainly dependent on the level of ROS, which is associated with glutathione depletion.

Reactive oxygen species generated from mitochondria are categorized into three groups: superoxide, $\mathrm{H}_{2} \mathrm{O}_{2}$, and hydro$\mathrm{xyl}$ radical. As shown in Figure $2 \mathrm{a}$ and $\mathrm{b}$, the scavenger for $\mathrm{H}_{2} \mathrm{O}_{2}$ and hydroxyl radical was effective, but SOD was not. We speculate that this ineffectiveness is due to the immediate conversion of superoxide to $\mathrm{H}_{2} \mathrm{O}_{2}$ by SOD or the inaccessibility of exogenous SOD to the mitochondria in which superoxide is generated.

There is some controversy surrounding the effectiveness of MPTP blocker in the rescue of CytC release and cell death. Many studies have shown the neuroprotective effects of CyA against neurotoxic agents. However, some reports have suggested that the release of CytC occurs through an outer membrane pore that does not require the MPT or mitochondrial swelling. ${ }^{19}$ Moreover, it was shown that CyA enhanced or induced apoptosis. ${ }^{20,21}$ In our conditions, the MPTP blockers,
CyA and dUbq, failed to halt CytC release and cell death, indicating that $\gamma$-secretase activation is not dependent on MPTP but on the release of CytC (Figure 4).

The importance of ROS generated by CytC release was confirmed by use of another oxidative stress inducer, DEM, which is known to increase intracellular oxidative stress by depleting glutathione, endogenous ROS scavenger together with thioredoxin. Treatment with DEM for $6 \mathrm{~h}$ did not induce cell death but significantly increased $\gamma$-secretase activity, suggesting that oxidative stress solely activates $\gamma$-secretase and that initiation of cell death is not required for the activation of $\gamma$-secretase (Figure $5 \mathrm{a}$ and $\mathrm{b}$ ). Moreover, $\mathrm{A} \beta$, known to increase oxidative stress by several mechanisms, also facilitated the activation of $\gamma$-secretase (Figure 5f). However, $\mathrm{H}_{2} \mathrm{O}_{2}$ treatment did not increase $\gamma$-secretase activity (data not shown), indicating that the mechanism governing $\gamma$-secretase activation differs from that of $\beta$-secretase under oxidative stress conditions, which is activated by $\mathrm{H}_{2} \mathrm{O}_{2}$ treatment. $^{12}$ This observation suggests that chronic oxidative stress is required for the activation of $\gamma$-secretase and that this is due to the more complicated regulatory mechanisms of $\gamma$-secretase, compared with $\beta$-secretase.

DNA damage-inducing agent-induced $\gamma$-secretase activation was shown to be induced by enhancing the formation of high molecular weight complex (Figure 6). This change of complex size can be mediated by several mechanisms like change of subcellular localization, post-translational modification, microenvironment and binding of complex modulators. In our preliminary experiments using immunoprecipitationcoupled Western blotting, DDIA treatment did not show any change in carbonylation, an oxidative modification marker, or phosphorylation of any component of $\gamma$-secretase (data not shown). However, as the sensitivity of Western blotting assay could not be enough to detect the subtle change of modification, we are investigating the modification of $\gamma$-secretase components using another method as well as other suggested possibilities.

Taken together with our previous report, death signals such as DDIA treatment induce the release of CytC through Bax translocation into the mitochondria, effecting apoptosome formation of CytC together with procaspase- 9 to activate downstream caspase activation, which is irrelevant to $\gamma$-secretase activation. Recently, it was reported that PS1 and APP are cleaved by caspases, which did not affect $\mathrm{A} \beta$ generation. ${ }^{8,29}$ Moreover, we also provided evidence that caspase inhibitor treatment did not attenuate activation of $\gamma$-secretase by DDIA treatment. ${ }^{9}$ At the same time, the mitochondrial electron transport chain lost electron acceptorCytC - produced large amount of ROS, which activated $\gamma$-secretase in a direct or indirect manner and thereby increased $\mathrm{A} \beta$ generation (Figure 7). These observations are consistent with the report that the antioxidant treatment could reduce the amyloid deposition in transgenic $A D$ model mice. ${ }^{30}$ Moreover, the most supportive in vivo evidences were recently presented by Arumugam et al. ${ }^{31}$ In this report, $\gamma$-secretase activity was increased in response to ischemic reperfusion, a well-known inducer of oxidative stress.

In some reports, it was shown that cells overexpressing mutant PS1 are more vulnerable to the stress conditions, and oxidative stress is involved in the increase of this 


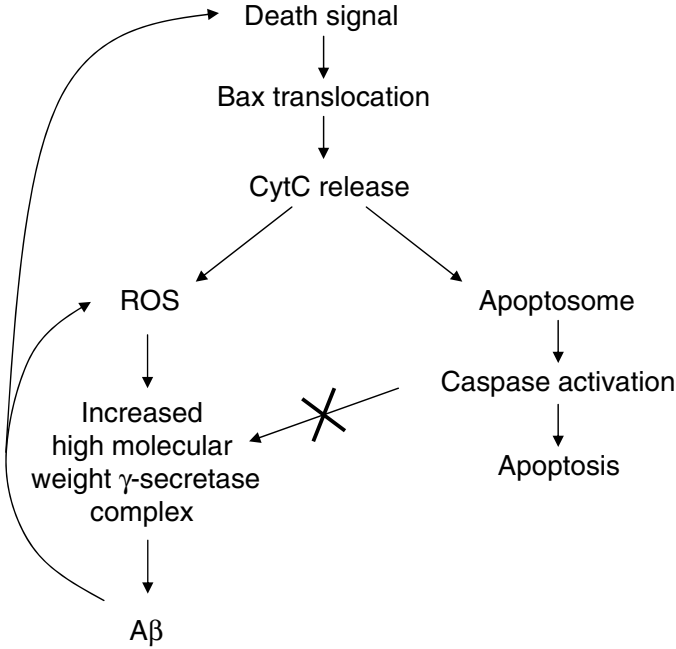

Figure 7 Schematic diagram of feed-back loop between ROS generation and $\mathrm{A} \beta$ generation

vulnerability. ${ }^{32}$ Moreover, recent report by Schuessel et al. ${ }^{33}$ presented in vivo evidence that familial mutation of PS1 increases ROS level and oxidative damage. As familial mutant PS1 has been known to reduce $\mathrm{A} \beta_{1-40},{ }^{34}$ the increased $\mathrm{A} \beta$ secretion in response to oxidative stress seemed to be a paradox compared to our results in which oxidative stress increases the generation of both $\mathrm{A} \beta$ species. However, the mechanism of $A \beta$-ratio alteration by mutant PS1 has not been fully established yet and our results were obtained using endogenous PS. Therefore, it needs to be confirmed how the $\gamma$-secretase complex containing mutant PS responds to oxidative stress.

Increased $\mathrm{A} \beta$ can act as another death signal, directly, inducing mitochondrial dysfunction or indirectly, increasing intracellular ROS generation through disruption of calcium homeostasis to form a positive feed-back loop, accelerating the production of $\mathrm{A} \beta$ (Figure 7). This vicious cycle could be the possible mechanism that turns on 'Amyloid cascade' in sporadic AD. As another explanation according to 'Alternate amyloid hypothesis', ${ }^{35,36}$ the increased $A \beta$ generation via $\gamma$-secretase activation during oxidative stress could be regarded as one of the cellular defense mechanism. Our data presented here are supportive for both hypotheses.

Taken together, these results indicate that DDIA-induced $\gamma$-secretase activation is dependent on oxidative stress augmented during DDIA-induced cell death, and reciprocally, increased $\mathrm{A} \beta$ may activate $\gamma$-secretase. On the basis of these results, we propose a positive feed-back loop between oxidative stress and $\mathrm{A} \beta$ generation mediated by $\gamma$-secretase activation as a mechanism of sporadic AD pathogenesis.

\section{Materials and Methods}

Chemicals. Eto, Cmt, NAC, GSH, L-NAME, STS, SOD, CAT, Fmt, Allo, Apo, CyA, dUbq, and DEM were purchased from Sigma-Aldrich. $A \beta_{1-42}$ synthetic peptide was purchased from Bachem.

Cell culture and drug treatment. $\mathrm{CHO}-\mathrm{C} 99$ cells, containing a reporter system for $\gamma$-secretase activity as described in our previous report, ${ }^{9}$ and
CHO-swAPP cells overexpressing human Swedish mutant APP were maintained in Dulbecco's modified Eagle's Medium (DMEM; HyClone) and F12 medium (HyClone), respectively, containing $10 \%$ fetal bovine serum (FBS; HyClone) with $0.1 \mathrm{mg} / \mathrm{ml}$ penicillin and streptomycin (P/S; Sigma-Aldrich). The primary cortical cultures were obtained from Tg2576 mouse brains (gifted from Dr. Hsiao-Ashe, University of Minnesota, MN) at postnatal day 1 and maintained in DMEM supplemented with $5 \% \mathrm{FBS}, 5 \%$ horse serum, $0.1 \mathrm{mg} / \mathrm{ml} \mathrm{P} / \mathrm{S}$, and $0.25 \mu \mathrm{g} / \mathrm{ml}$ Fungizone (Sigma-Aldrich) at $37^{\circ} \mathrm{C}$ for 7 days before treatment. DDIAs were diluted in DMEM containing $0.1 \mathrm{mg} / \mathrm{ml} \mathrm{P} / \mathrm{S}$, administered to $\mathrm{CHO}-\mathrm{C} 99$ cells at the indicated concentration for 48 or $24 \mathrm{~h}$ (serum starvation for $24 \mathrm{~h}$ was performed prior to $\mathrm{Cmt}$ treatment).

Transfection. Transfection of the CHO-C99 cells was performed using Lipofectamine $^{\mathrm{TM}}$ LTX according to the manufacturer's protocol (Invitrogen). Briefly, cells were seeded in 12 wells $\left(2 \times 10^{5}\right.$ cells per well) for the luciferase assay and in $100-\mathrm{mm}$ culture plates ( $80 \%$ confluent) for fractionation of cytosolic proteins $24 \mathrm{~h}$ prior to transfection. The human Hsp70 cDNA construct was mixed with Lipofectamine LTX in OptiMEM (Invitrogen). After $30 \mathrm{~min}$ of incubation, the mixture was then added to the cell culture medium for 1 day and treated as above.

Luciferase reporter assay. $\mathrm{CHO}-\mathrm{C} 99$ cells were incubated in 12-well plates at a density of $2 \times 10^{5}$ cells per well for 1 day with drug treatments as described. After the treatment, cells were lysed with $1 \times$ Passive Lysis Buffer (Promega). Protein concentrations were determined using a BCA kit (Pierce). One hundred microliters of the luciferase substrates (Promega) were mixed with $10 \mu \mathrm{g}$ of the lysate. The luciferase gene expression level was determined using a luminometer (Lumet; Berthold Technologies).

Quantitation of intracellular glutathione. Total glutathione levels were measured using the DTNB-GSSG reductase recycling assay. ${ }^{37} \mathrm{CHO}-\mathrm{C} 99$ cells treated with Eto, $\mathrm{Cmt}$, or DEM were washed with phosphate-buffered saline (PBS), detached, and counted. A total of $2 \times 10^{7}$ cells were pelleted and resuspended in $100 \mu$ lice-cold $5 \% 5$-sulphosalicylic acid. After centrifugation, cleared supernatants were mixed with $150 \mu \mathrm{l}$ of assay mixture $(95 \mathrm{mM}$ potassium phosphate buffer $(\mathrm{pH}$ 7.0), $0.95 \mathrm{mM}$ EDTA, $38 \mu \mathrm{g} / \mathrm{ml}$ NADPH, $31 \mu \mathrm{g} / \mathrm{ml}$ DTNB, and $0.115 \mathrm{U} / \mathrm{ml}$ glutathione reductase) and incubated for $5 \mathrm{~min}$ at room temperature (RT). After adding NADPH, absorbance was measured at $412 \mathrm{~nm}$ with kinetic readings at $1 \mathrm{~min}$ intervals for 5 min using a plate reader (PowerWave Xs; BIO-TEC).

Measurement of intracellular ROS. Intracellular ROS level was measured using carboxy- $\mathrm{H}_{2} \mathrm{DCFDA}$ (DCFDA) fluorescence according to the previous report. ${ }^{38}$ Briefly, cells grown in 12-well plates were treated with DDIA, and cells were then incubated for $15 \mathrm{~min}$ with the ROS/RNS-sensitive fluorophore DCFDA $(5 \mu \mathrm{g} / \mathrm{ml})$. The cells were then immediately washed with PBS, detached, and counted. The same numbers of cells were pelleted and resuspended in $100 \mu \mathrm{l}$ ice-cold KrebsRinger's solution. Fluorescence was measured at excitation $493 \mathrm{~nm}$ and emission $522 \mathrm{~nm}$ using a fluorometer (LS-55; PerkinElmer)

A $\beta$ ELISA. Human $A \beta_{40}$ and $A \beta_{42}$ levels were quantified using a commercially available ELISA kit from Biosource as guided by manufacturer. In brief, conditioned media from DDIA-treated CHO-swAPP cells were loaded onto plates coated with $\mathrm{A} \beta \mathrm{N}$-terminal-specific antibody and incubated with $\mathrm{A} \beta \mathrm{C}$-terminal-specific antibody for $4 \mathrm{~h}$ at RT. $A \beta$ was detected by incubating for $30 \mathrm{~min}$ at RT with horseradish peroxidase-conjugated secondary antibody. ELISA plates were developed using a color reaction, and the absorbance was read at $450 \mathrm{~nm}$ using a plate reader (POWER-XS; BIO-TEK)

MTT assay. Reduction of 3-(4,5-dimethyl-2-thiazolyl)-2,5-diphenyl-2Htetrazolium bromide (MTT) by mitochondrial reductase was carried out using protocols based on a previous report, with slight modifications. ${ }^{39}$ After treatment with DDIA, $10 \mu \mathrm{l}$ of $5 \mathrm{mg} / \mathrm{ml} \mathrm{MTT}$ in phosphate buffer solution was added to the cell culture, which was incubated at $37^{\circ} \mathrm{C}$ in $5 \% \mathrm{CO}_{2}$ for $4 \mathrm{~h}$. After evacuation of the culture medium, $100 \mu \mathrm{l}$ DMSO was subsequently added to the cells and the colorimetric determination of MTT was made at $570 \mathrm{~nm}$. The absorbance obtained by the addition of vehicle was taken as $100 \%$.

Western blotting. Total protein extracts were prepared with RIPA buffer for detection of APP and Hsp70 levels. To measure CytC release from mitochondria, cytosolic fractions were prepared using the Mitochondrial Fractionation Kit (Active 
Motif). In brief, the treated cells were washed twice with ice-cold PBS, scraped, harvested by centrifugation, and resuspended in ice-cold $1 \times$ cytosolic buffer homogenized with a Dounce homogenizer, and nuclear and membrane fractions were removed by serial centrifugation at 1700 and 13000 r.p.m., respectively. The resulting supernatants were used as the cytosolic fraction. For all blots, protein levels were determined using a BCA protein assay kit (Pierce). Thirty micrograms of proteins were loaded into each well for each blot. We used $8 \%$ Tris-glycine polyacrylamide gels for full-length APP and Nct, $10 \%$ for $\mathrm{Hsp} 70$, and $15 \%$ for CytC. For PS1-C-terminal fragment, Aph-1a, Pen-2, 12\% Tricine polyacrylamide gels were used. The monoclonal antibodies against APP (22C11, 1:3000; Chemicon), CytC (1:1000; BD bioscience), Heat shock protein 70 (1:1000; Santa Cruz Biotechnologies Inc.), $\beta$-actin (1:3000; Sigma-Aldrich), and PS1-loop (1:3000; Chemicon) and the polyclonal antibodies against Aph-1a (1:3000; Affinity Bioreagent), and Pen-2 (1:3000; Calbiochem) were used for Western blotting.

Blue native-polyacrylamide gel electrophoresis. For BN-PAGE, crude membrane fraction was obtained. In brief, the harvested cells as above were resuspended in ice-cold hypotonic buffer (10 mM Tris- $\mathrm{HCl}(\mathrm{pH} 7.4), 1 \mathrm{mM}$ EDTA, $1 \mathrm{mM}$ EGTA, $1 \mathrm{mM}$ PMSF, $1 \times$ Protease Inhibitor Cocktail (Sigma)) and kept for $30 \mathrm{~min}$ on ice. After homogenization with a Dounce homogenizer, nuclear fractions were removed by centrifugation at 1700 r.p.m. The resulting supernatants were centrifuged at 13000 r.p.m. for $30 \mathrm{~min}$ at $4^{\circ} \mathrm{C}$. The pellet was washed once with hypotonic buffer and solubilized with hypotonic buffer containing $0.5 \%$ CHAPS for $30 \mathrm{~min}$ at $4^{\circ} \mathrm{C}$. After centrifugation at 13000 r.p.m. for $30 \mathrm{~min}$ at $4^{\circ} \mathrm{C}$, the supernatants were used as the crude membrane fraction. BN-PAGE was performed as previously described with slight modifications. ${ }^{40}$ Ten or $40 \mu \mathrm{g}$ of the crude membrane fraction was mixed with $1: 10$ volume of $5 \%$ Serva blue G $(100 \mathrm{mM}$ BisTris- $\mathrm{HCl}$ (pH 7.0), $0.5 \mathrm{M}$ 6-amino-n-caproic acid, 30\% glycerol) and loaded onto 1-mm-thick 7\% acrylamide gels. Gel-transferred membranes were immunodecorated with anti-human pen-2 polyclonal antibody $(1: 3000$; Calbiochem)

Statistical analysis. For statistical analysis, one-way ANOVA tests were performed and followed by the Bonferroni post-test $\left({ }^{\star} P<0.05\right.$, ${ }^{\star \star} P<0.01$, ${ }^{* \star *} P<0.001$ versus vehicle-treated sample; ${ }^{\#} P<0.05$, ${ }^{\# \#} P<0.01$, \#\#\# $P<0.001$ versus DDIA-treated sample).

Acknowledgements. We thank Dr. Karen Hsiao-Ashe (University of Minnesota, MN) for Tg2576 mice, Dr. Yong-Keun Jung (Gwangju Institute of Science of Technology, Gwangju, Korea) for the C99-GV construct, and Dr. Jung Seon Seo (Seoul National University, Seoul, Korea) for the Hsp70 construct and antibody. This work was supported by a Korean Research Foundation Grant (MOEHRD) (KRF-2006-351-C00030) for SMJ; and grants from 21C Frontier Functional Proteomics Project (FPR05C2-010), New drug target discovery project (2006-02502), and AARC program project from KOSEF for IMJ.

1. Yankner BA. Mechanisms of neuronal degeneration in Alzheimer's disease. Neuron 1996; 16: 921-932.

2. Selkoe DJ. Toward a comprehensive theory for Alzheimer's disease. hypothesis: Alzheimer's disease is caused by the cerebral accumulation and cytotoxicity of amyloid beta-protein. Ann N Y Acad Sci 2000; 924: 17-25.

3. Parks AL, Curtis D. Presenilin diversifies its portfolio. Trends Genet 2007; 23: 140-150.

4. Shen J, Bronson RT, Chen DF, Xia W, Selkoe DJ, Tonegawa S. Skeletal and CNS defects in Presenilin-1-deficient mice. Cell 1997; 89: 629-639.

5. Saura CA, Choi SY, Beglopoulos V, Malkani S, Zhang D, Shankaranarayana Rao BS et al. Loss of presenilin function causes impairments of memory and synaptic plasticity followed by age-dependent neurodegeneration. Neuron 2004; 42: 23-36.

6. Wong GT, Manfra D, Poulet FM, Zhang Q, Josien H, Bara T et al. Chronic treatment with the gamma-secretase inhibitor LY-411, 575 inhibits beta-amyloid peptide production and alters lymphopoiesis and intestinal cell differentiation. $J$ Biol Chem 2004; 279 12876-12882.

7. Galli C, Piccini A, Ciotti MT, Castellani L, Calissano P, Zaccheo D et al. Increased amyloidogenic secretion in cerebellar granule cells undergoing apoptosis. Proc Natl Acad Sci USA 1998; 95: 1247-1252.

8. Tesco G, Koh YH, Tanzi RE. Caspase activation increases beta-amyloid generation independently of caspase cleavage of the beta-amyloid precursor protein (APP). J Biol Chem 2003; 278: 46074-46080.
9. Jin SM, Cho HJ, Jung MW, Mook-Jung I. DNA damage-inducing agent-elicited gammasecretase activity is dependent on Bax/Bcl-2 pathway but not on caspase cascades. Cell Death Differ 2007; 14: 189-192.

10. Kroemer G, Reed JC. Mitochondrial control of cell death. Nat Med 2000; 6: 513-519.

11. Perry G, Nunomura A, Hirai K, Takeda A, Aliev G, Smith MA. Oxidative damage in Alzheimer's disease: the metabolic dimension. Int J Dev Neurosci 2000; 18: 417-421.

12. Tamagno E, Bardini $P$, Obbili A, Vitali A, Borghi R, Zaccheo D et al. Oxidative stress increases expression and activity of BACE in NT2 neurons. Neurobiol Dis 2002; 10: 279-288.

13. Yatin SM, Aksenova M, Aksenov M, Markesbery WR, Aulick T, Butterfield DA. Temporal relations among amyloid beta-peptide-induced free-radical oxidative stress, neuronal toxicity, and neuronal defensive responses. J Mol Neurosci 1998; 11: 183-197.

14. Parks JK, Smith TS, Trimmer PA, Bennett Jr JP, Parker Jr WD. Neurotoxic Abeta peptides increase oxidative stress in vivo through NMDA-receptor and nitric-oxide-synthase mechanisms, and inhibit complex IV activity and induce a mitochondrial permeability transition in vitro. J Neurochem 2001; 76: 1050-1056.

15. Tamagno E, Bardini $P$, Guglielmotto $M$, Danni $O$, Tabaton $M$. The various aggregation states of beta-amyloid 1-42 mediate different effects on oxidative stress, neurodegeneration, and BACE-1 expression. Free Radic Biol Med 2006; 41: 202-212.

16. Barnham KJ, Masters CL, Bush Al. Neurodegenerative diseases and oxidative stress. Nat Rev Drug Discov 2004; 3: 205-214.

17. Vaughn AE, Deshmukh M. Essential postmitochondrial function of $p 53$ uncovered in DNA damage-induced apoptosis in neurons. Cell Death Differ 2007; 14: 973-981.

18. Stankiewicz AR, Lachapelle G, Foo CP, Radicioni SM, Mosser DD. Hsp70 inhibits heatinduced apoptosis upstream of mitochondria by preventing Bax translocation. J Biol Chem 2005; 280: 38729-38739.

19. Andreyev AY, Fahy B, Fiskum G. Cytochrome $c$ release from brain mitochondria is independent of the mitochondrial permeability transition. FEBS Lett 1998; 439: 373-376.

20. Fall CP, Bennett Jr JP. MPP+ induced SH-SY5Y apoptosis is potentiated by cyclosporin A and inhibited by aristolochic acid. Brain Res 1998; 811: 143-146.

21. McDonald JW, Goldberg MP, Gwag BJ, Chi SI, Choi DW. Cyclosporine induces neuronal apoptosis and selective oligodendrocyte death in cortical cultures. Ann Neurol 1996; 40: 750-758.

22. Butterfield DA, Reed T, Newman SF, Sultana R. Roles of amyloid beta-peptide-associated oxidative stress and brain protein modifications in the pathogenesis of Alzheimer's disease and mild cognitive impairment. Free Radic Biol Med 2007; 43: 658-677.

23. De Felice FG, Velasco PT, Lambert MP, Viola K, Fernandez SJ, Ferreira ST et al. Abeta oligomers induce neuronal oxidative stress through an $\mathrm{N}$-methyl-D-aspartate receptordependent mechanism that is blocked by the Alzheimer drug memantine. J Biol Chem 2007; 282: 11590-11601.

24. Evin G, Canterford LD, Hoke DE, Sharples RA, Culvenor JG, Masters CL. Transition-state analogue gamma-secretase inhibitors stabilize a $900 \mathrm{kDa}$ presenilin/nicastrin complex. Biochemistry 2005; 44: 4332-4341.

25. Paola D, Domenicotti $C$, Nitti M, Vitali A, Borghi R, Cottalasso D et al. Oxidative stress induces increase in intracellular amyloid beta-protein production and selective activation of betal and betall PKCs in NT2 cells. Biochem Biophys Res Commun 2000; 268: 642-646.

26. Frederikse PH, Garland D, Zigler Jr JS, Piatigorsky J. Oxidative stress increases production of beta-amyloid precursor protein and beta-amyloid (Abeta) in mammalian lenses, and Abeta has toxic effects on lens epithelial cells. J Biol Chem 1996; 271 : 10169-10174

27. Apelt J, Bigl M, Wunderlich $P$, Schliebs R. Aging-related increase in oxidative stress correlates with developmental pattern of beta-secretase activity and beta-amyloid plaque formation in transgenic Tg2576 mice with Alzheimer-like pathology. Int J Dev Neurosci 2004: 22: 475-484

28. Chandra J, Samali A, Orrenius S. Triggering and modulation of apoptosis by oxidative stress. Free Radic Biol Med 2000; 29: 323-333.

29. Hansson CA, Popescu BO, Laudon H, Cedazo-Minguez A, Popescu LM, Winblad B et al. Caspase cleaved presenilin-1 is part of active gamma-secretase complexes. J Neurochem 2006; 97: 356-364

30. Sung S, Yao Y, Uryu K, Yang H, Lee VM, Trojanowski JQ et al. Early vitamin E supplementation in young but not aged mice reduces Abeta levels and amyloid deposition in a transgenic model of Alzheimer's disease. FASEB J 2004; 18: 323-325.

31. Arumugam TV, Chan SL, Jo DG, Yilmaz G, Tang SC, Cheng A et al. Gamma secretasemediated Notch signaling worsens brain damage and functional outcome in ischemic stroke. Nat Med 2006; 12: 621-623.

32. Keller JN, Guo Q, Holtsberg FW, Bruce-Keller AJ, Mattson MP. Increased sensitivity to mitochondrial toxin-induced apoptosis in neural cells expressing mutant presenilin-1 is linked to perturbed calcium homeostasis and enhanced oxyradical production. $J$ Neurosci 1998; 18: 4439-4450.

33. Schuessel K, Frey C, Jourdan C, Keil U, Weber CC, Muller-Spahn F et al. Aging sensitizes toward ROS formation and lipid peroxidation in PS1M146L transgenic mice. Free Radic Biol Med 2006; 40: 850-862.

34. Citron M, Westaway D, Xia W, Carlson G, Diehl T, Levesque G et al. Mutant presenilins of Alzheimer's disease increase production of 42-residue amyloid beta-protein in both transfected cells and transgenic mice. Nat Med 1997; 3: 67-72. 
35. Lee HG, Casadesus G, Zhu X, Takeda A, Perry G, Smith MA. Challenging the amyloid cascade hypothesis: senile plaques and amyloid-beta as protective adaptations to Alzheimer disease. Ann NY Acad Sci 2004; 1019: 1-4.

36. Lee HG, Zhu X, Nunomura A, Perry G, Smith MA. Amyloid beta: the alternate hypothesis. Curr Alzheimer Res 2006; 3: 75-80

37. Cuozzo JW, Kaiser CA. Competition between glutathione and protein thiols for disulphidebond formation. Nat Cell Biol 1999; 1: 130-135.

38. Sawada M, Nakashima S, Kiyono T, Nakagawa M, Yamada J, Yamakawa H et al. p53 regulates ceramide formation by neutral sphingomyelinase through reactive oxygen species in human glioma cells. Oncogene 2001; 20: 1368-1378.
39. Murakami K, Irie K, Morimoto A, Ohigashi H, Shindo M, Nagao M et al. Neurotoxicity and physicochemical properties of $A\{$ beta\} mutant peptides from cerebral amyloid angiopathy: implication for the pathogenesis of cerebral amyloid angiopathy and alzheimer's disease. J Biol Chem 2003; 278: 46179-46187.

40. Schagger $H$, Cramer WA, von Jagow $G$. Analysis of molecular masses and oligomeric states of protein complexes by blue native electrophoresis and isolation of membrane protein complexes by two-dimensional native electrophoresis. Anal Biochem 1994; 217: 220-230.

Supplementary Information accompanies the paper on Cell Death and Differentiation website (http://www.nature.com/cdd) 